\title{
Gender Differences in the Association between Sleep Duration and Body Composition: The Cardia Study
}

\author{
Marie-Pierre St-Onge, ${ }^{1}$ Suzanne Perumean-Chaney, ${ }^{2}$ Renee Desmond, ${ }^{3}$ Cora E. Lewis, ${ }^{4}$ \\ Lijing L. Yan, ${ }^{5,6}$ Sharina D. Person, ${ }^{4}$ and David B. Allison ${ }^{2}$ \\ ${ }^{1}$ New York Obesity Research Center, St. Luke's/Roosevelt Hospital, 1090 Amsterdam Avenue, suite 14D, New York, \\ NY 10025, USA \\ ${ }^{2}$ Department of Biostatistics, University of Alabama at Birmingham, Birmingham, AL 35294, USA \\ ${ }^{3}$ Division of Medicine, University of Alabama at Birmingham, Birmingham, AL 35294, USA \\ ${ }^{4}$ Division of Preventive Medicine, University of Alabama at Birmingham, Birmingham, AL 35294, USA \\ ${ }^{5}$ Department of Preventive Medicine, Northwestern University, Chicago, IL 60611, USA \\ ${ }^{6}$ Department of Health Economics and Management, Guanghua School of Management, Peking University, \\ Beijing 100871, China \\ Correspondence should be addressed to Marie-Pierre St-Onge, ms2554@columbia.edu
}

Received 25 June 2009; Accepted 14 October 2009

Academic Editor: Jessica A. Mong

Copyright () 2010 Marie-Pierre St-Onge et al. This is an open access article distributed under the Creative Commons Attribution License, which permits unrestricted use, distribution, and reproduction in any medium, provided the original work is properly cited.

Sleep duration has been inversely associated with body mass index (BMI). We examined the relationship between self-reported sleep duration and BMI, waist circumference, and percent body fat in Black and White individuals from the CARDIA study. BoxTidwell regression models were adjusted for age and race (Model 1), additional lifestyle and demographic variables (Model 2), and physical activity (Model 3). There were significant interactions between sleep and gender for the main outcome variables. In men, there was a trend for an inverse relationship between reported sleep duration and BMI in Model $2(\beta=-0.20, P=$ $.053)$ but not model $3(\beta=-0.139, P=.191)$. In women, inverse relationships were observed between sleep duration and BMI $(\beta=-0.294, P=.005)$ and waist circumference $(\beta=-0.442, P=.059)$, in Model 2 . These associations became nonsignificant in model 3 (BMI: $\beta=-0.172, P=.084$; waist circumference: $\beta=-0.161, P=.474$ ). Our results are consistent with previous findings that sleep is associated with BMI and other body composition variables. However, the relationship between self-reported sleep duration and body composition may be stronger in women than in men.

\section{Introduction}

Physical activity and dietary patterns have received much attention in attempts to explain the rise in obesity of past decades; however, many other factors have been identified that may have contributed to the obesity epidemic that we observe today [1]. One contributor receiving much interest recently is sleep debt. In a 2004 survey, approximately 63\% of adults reported sleeping 7-8 h/night and almost 30\% averaged less than $6 \mathrm{~h} /$ night [2]. In the Sleep Heart Health Study, mean sleep duration was reportedly slightly over $7 \mathrm{~h} /$ night in both men and women [3]. In the Coronary Artery Risk Development in Young Adults (CARDIAs) study, young adults were getting approximately 6 hours of sleep/night [4] with Black men and women sleeping, on average, about $1 \mathrm{~h} /$ night less than White men and women (about 5.5 versus $6.4 \mathrm{~h} /$ night).

Such short reported sleeping times may be of concern in the context of an obesity epidemic since several studies have found that sleep duration is inversely associated with body mass index (BMI, in $\mathrm{kg} / \mathrm{m}^{2}$ ) [5-8]. Data from the National Health and Nutrition Examination Survey I (NHANES I) showed that young adults getting $<7$ hours of sleep/night had higher BMI and were more likely to be obese than those sleeping $7 \mathrm{~h} /$ night or more [9]. Similar findings are observed in children and adolescents [10-13]. Furthermore, 
data from the Nurses' Health Study show greater weight gain in women sleeping less than $7 \mathrm{~h} /$ night compared with those sleeping at least $7 \mathrm{~h} /$ night [14]. Women sleeping 7 $8 \mathrm{~h} / \mathrm{night}$ also had the lowest risk for major weight gain ( $\geq 15 \mathrm{~kg}$ over 16 years) and sleeping $\geq 7 \mathrm{~h} /$ night was not associated with an increased risk of developing obesity in normal weight women whereas sleeping 5 or $6 \mathrm{~h} /$ night was. Similarly, in the Quebec Family Study, those who reported sleeping 5-6 h/night gained approximately $2 \mathrm{~kg}$ more over a 6-year follow-up period than those who reported sleeping 7$8 \mathrm{~h} /$ night [15].

Despite the large number of epidemiological studies linking obesity and short sleep duration [16], there is a paucity of data carefully examining the relationship between body composition and sleep duration in adults. Strengths of our cohort study include the presence of waist circumference, and percent body fat data from dual energy X-ray absorptiometry (DXA) as well as the inclusion of both Black and White individuals. Waist circumference contributes independently to the prediction of visceral adipose tissue [17] and it is therefore of interest to assess its relationship with sleep duration. The main objective of this study was to examine relationships between self-reported sleep duration and BMI, waist circumference, and percent body fat in the CARDIA cohort. We hypothesized that short sleep duration would be associated with higher BMI, waist circumference and percent body fat. Secondary objectives were to determine whether body composition also showed similar relationships with sleep duration between Black and White adults and between men and women. This study is important since it is one of the few studies to examine the impact of sleep duration on body composition indices in both Black and White men and women. It is interesting to note that Black individuals tend to be more overweight and obese than Whites [18] and also tend to sleep less [4]. It is possible that sleep duration may have a greater impact on obesity status in Blacks than Whites, yet this has not been examined. Similarly, gender differences in the impact of sleep duration on obesity status have been noted in children but not extensively studied in adults [19].

\section{Methods}

Data for the analyses reported here are from the CARDIA Study, a cohort study established to examine the determinants and evolution of cardiovascular disease risk factors in young Black and White adults. A total of 5115 men and women, aged 18-30 years, were recruited from 4 centers in 1985-1986: Birmingham, AL (University of Alabama at Birmingham), Chicago, IL (Northwestern University), Minneapolis, MN (University of Minnesota), and Oakland, CA (Kaiser Permanente Oakland). Subjects were examined at baseline and years 2, 5, 7, 10, and 15. At the time of preparation of this manuscript, year 20 data were not available and only cross-sectional analyses are reported here. Furthermore, sleep was assessed only at examination Year 15 , preventing us from assessing longitudinal relationships with body composition data from prior examination years.
All subjects provided written informed consent at each visit and study protocols were approved by the Institutional Review Board of each institution. Details of the recruitment and study procedures are reported elsewhere [20]. We certify that all applicable institutional and governmental regulations concerning the ethical use of human volunteers were followed during this research.

For the present study, we examined the relationship between sleep duration and indices of body composition from examination at year 15, when subjects were 33-45 years of age. Of the initial cohort of 5115 subjects, 3672 (72\%) returned for the year 15 visit. We excluded subjects who had low $(<18.5)$ and extremely high $(>45)$ BMI, implausible sleep data $(\geq 15 \mathrm{~h} / \mathrm{night})$, those who reported drinking more than 3 standard deviations above the mean alcoholic beverage consumption ( $>30$ drinks per week), women who were pregnant or breastfeeding, and subjects with missing data. Our final sample size was 3473 subjects for the anthropometric analyses (BMI and waist circumference). DXA was only done at the Birmingham and Oakland sites on a subsample of the study population, allowing analyses examining the relationship between sleep duration and body fat in 320 participants [21].

2.1. Demographics and Lifestyle Information. Demographic characteristics, age, sex, race, education level, and income level, were self-reported on standardized questionnaires. The information used in this study was collected at the year 15 examination. Education level was determined by obtaining the highest grade or year of regular school completed and was included in the models as a continuous variable (range $1-20+$ years). Income level was categorized as total combined family income for the past 12 months and coded ordinally $(1=<\$ 5000,2=\$ 5000-11999,3=\$ 12000-15999$, $4=\$ 16000-24999,5=\$ 25000-34999,6=\$ 35000-$ $49999,7=\$ 50000-74999,8=\$ 75000-99999$, and $9=\geq \$ 100000)$. Data are presented with groups $1-4$ combined $(<\$ 25000), 5-7$ combined (\$25 000-74 999), and 8 -9 combined ( $\geq \$ 75000$ ). Leisure-time physical activity and work-related physical activity were assessed using a validated interview-administered questionnaire.

2.2. Body Composition Measurements. Weight (to the nearest $0.2 \mathrm{~kg}$ ) and height (to the nearest $0.5 \mathrm{~cm}$ ) were recorded with subjects wearing light clothing and without shoes. BMI was calculated as weight in $\mathrm{kg}$ divided by the square of height in meters. Waist circumference was measured at the level of minimal abdominal girth (to the nearest $0.5 \mathrm{~cm}$ ) and recorded as the average of 2 measurements. Body composition was measured using DXA QDR-2000 scanner (Hologic, Inc., Waltham, MA). Daily phantom scanning was done to ensure consistent data acquisition throughout the study.

2.3. Sleep Questionnaire. A standardized sleep questionnaire was administered at 15 years of followup. The questionnaire included the question: "During the past month, how many hours of actual sleep did you get at night? (this may be 
different than the number of hours you spend in bed)." The answer to this question was used to determine self-reported sleep duration.

2.4. Statistical Analyses. Descriptive statistics consisted of frequencies, percentages, means, and standard deviations. The relationship between continuous predictors and anthropometric outcomes was assessed with regression models and for categorical variables with the Cochran-Armitage trend test.

To initially assess the association of sleep with body composition variables, Box-Tidwell regressions were conducted [22]. Nonlinear relationships were noted for both sleep duration and age with the four dependent variables (weight, BMI, waist, and percent body fat). The Box-Tidwell procedure was utilized to identify an appropriate power transformation of the independent and dependent variables to linearize relationships. To adjust for the nonlinear relationship, all four dependent variables were log-transformed. Once the transformations were selected in the Box-Tidwell regressions, the new transformed variables were included in ordinary multiple linear regressions. The transformed variables were rescaled by linear transformation to their original mean and variance for ease of interpretation and presentation. Table 1 shows the respective transformations used for sleep and age by gender. There was a significant interaction between gender and sleep for the main outcome variables and therefore the models were stratified by gender.

The appropriate transformed variables were used in three regression models for each dependent variable. In Model 1, the impact of sleep on the dependent variable was adjusted for age and race. Model 2 was further adjusted for lifestyle (smoking, alcohol intake) and demographic (education level, income) factors. These lifestyle variables are routinely included in models assessing the impact of one behavior on body composition [14]. Factors that did not significantly impact the dependent variable for both men and women were removed for the analyses. Model 3 was additionally adjusted for physical activity level. The beta $(\beta)$ coefficients reported are unstandardized estimated regression coefficients calculated using predictor variables after they have been transformed (as described above) and then rescaled via linear transformations to their original mean and variance to ease interpretation. For instance, a 1-hour increase in sleep changes the dependent variable by $\beta$ units. All models were tested for interactions between race and sleep and no significant interactions were found. Therefore the estimates reflect the combined racial groupings. A twotailed $\alpha$ level of 0.05 was considered statistically significant. Data were analyzed using SAS software for Windows version 9.1 (SAS Institute Inc., Cary, NC).

\section{Results}

A total of 1585 men and 1888 women were included in the main analyses. For the analyses using data from DXA measurements, the sample included 159 men and 161 women. Table 2 shows subject characteristics by gender and race for the main analyses. Most comparisons were statistically significant. In general, women were older than men, weighed less, had higher percent body fat, drank less alcohol and smoked less, reported sleeping longer, and were more inactive than men. Generally, Blacks were younger, heavier, had lower education and income level, reported sleeping less, were less physically active, and smoked more than Whites.

Sleep duration tended to be inversely associated with BMI in men in Model $1(\beta=-0.20, P=.053)$ and after controlling for other lifestyle and physiologic variables in Model $2(\beta=-0.198, P=.068)$ (Table 3). In Model 3, after including physical activity, sleep was not significantly associated with $\mathrm{BMI}$ in men $(\beta=-0.139, P=$ .191). In model 3, race, smoking, alcohol intake, education level, family income, and physical activity level were all significantly associated with BMI. In women, the inverse association between sleep duration and BMI was significant after controlling for age and race $(\beta=-0.332, P=$ $.002)$ and other lifestyle and physiologic variables $(\beta=$ $-0.294, P=.005)$. However, after physical activity was added to the model, the association between sleep and BMI became nonsignificant $(\beta=-0.172, P=.084)$. In women, in model 3 , age, race, education level, family income, working full time, and physical activity level were all significantly associated with BMI.

There was no statistically significant association between sleep duration and waist circumference in men, although the magnitude and direction of the sample slope was similar to that observed in women (Table 4). In women, waist circumference was significantly inversely associated with sleep duration in model $1(\beta=-0.543, P=.022)$. This relationship was no longer statistically significant when we further controlled for other lifestyle and demographic variables, but was similar in magnitude and nearly statistically significant in model $2(\beta=-0.442, P=.059)$ but not in model $3(\beta=-0.161, P=.474)$. Percent body fat was not significantly associated with sleep duration in neither men nor women.

\section{Discussion}

This is one of the few studies to examine the relationship between sleep and body composition variables beyond body weight and BMI in adults. Furthermore, it is the only study to date to examine the relationship between sleep and body composition in a bi-racial population of Blacks and Whites. As such, this is the first study to examine whether sleep duration is related to waist circumference and percent body fat in Black and White adults.

Few studies to date have examined the relationship between waist circumference and sleep in adults. In the Better Health for Better Hong Kong campaign, waist circumference was inversely related to sleep duration [5], in agreement with our data in women. In men, although the association was not statistically significant, the magnitude and direction of the association between waist circumference and sleep duration was similar to that observed in women. However, in a sample 
TABle 1: Transformations for sleep and age by gender.

\begin{tabular}{lcccr}
\hline Dependent Variable & \multicolumn{2}{c}{ Men } & \multicolumn{2}{c}{ Women } \\
& Sleep & Age & Sleep & Age \\
\hline BMI & 0.25 power & Square root & Square root & Log \\
Waist circumference & Log & Log & Log & 0.75 power \\
Percent Body Fat & Square root & None & 0.25 power \\
\hline
\end{tabular}

TABLE 2: Participant characteristics by gender and race.

\begin{tabular}{|c|c|c|c|c|}
\hline Characteristic & White men $(n=897)$ & Black men $(n=688)$ & White women $(n=962)$ & Black women $(n=926)$ \\
\hline & Mean $(\mathrm{sd})$ & Mean $(\mathrm{sd})$ & Mean $(\mathrm{sd})$ & Mean $(\mathrm{sd})$ \\
\hline Age (years) & $40.67(3.36)$ & $39.47(3.73)^{*}$ & $40.79(3.36)$ & $39.67(3.84)^{*}$ \\
\hline Weight (lbs) & $193.95(34.21)$ & $199.85(41.49)^{*}$ & $158.0(35.20)$ & $183.14(39.99)^{*}$ \\
\hline BMI $\left(\mathrm{kg} / \mathrm{m}^{2}\right)$ & $27.65(4.34)$ & $28.59(5.24)^{*}$ & $26.23(5.57)$ & $30.66(6.26)^{*}$ \\
\hline Waist circumference $(\mathrm{cm})$ & $93.67(11.59)$ & $92.88(12.55)$ & $80.76(12.85)$ & $88.74(13.49)^{*}$ \\
\hline Body fat $(\%)^{1}$ & $26.88(6.26)$ & $24.40(7.82)^{*}$ & $38.25(9.70)$ & $43.81(7.46)^{*}$ \\
\hline Education level (years) & $15.69(2.66)$ & $13.71(2.21)^{*}$ & $15.82(2.40)$ & $14.09(2.19)^{*}$ \\
\hline Alcohol intake (drinks/wk) & $4.92(6.20)$ & $4.69(6.91)$ & $3.16(4.84)$ & $1.90(4.08)^{*}$ \\
\hline \multirow[t]{2}{*}{ Sleep duration (h/night) } & $6.65(1.00)$ & $6.26(1.37)^{*}$ & $6.84(1.09)$ & $6.28(1.48)^{*}$ \\
\hline & $\mathrm{N}(\%)$ & $\mathrm{N}(\%)$ & $\mathrm{N}(\%)$ & $\mathrm{N}(\%)$ \\
\hline \multicolumn{5}{|l|}{ Family income } \\
\hline$<\$ 5000-\$ 24999$ & $61(6.8)$ & $145(21.6)^{*}$ & $75(7.9)$ & $246(27.1)^{*}$ \\
\hline$\$ 25000-\$ 74999$ & $361(40.3)$ & $345(51.7)$ & $431(45.0)$ & $478(52.6)$ \\
\hline$\$ 75000-\geq \$ 100000$ & $474(52.9)$ & $178(26.7)$ & $450(47.1)$ & $186(20.3)$ \\
\hline \multicolumn{5}{|l|}{ Full-time work } \\
\hline Yes & $801(89.3)$ & $539(78.7)^{*}$ & $559(58.1)$ & $695(75.5)^{*}$ \\
\hline No & $96(10.7)$ & $146(21.3)$ & 403 (41.9) & $226(24.5)$ \\
\hline \multicolumn{5}{|l|}{ Difficulty paying for basics } \\
\hline Very hard & $12(1.3)$ & $20(2.9)^{*}$ & $20(2.1)$ & $40(4.4)^{*}$ \\
\hline Hard & $13(1.5)$ & $24(3.5)$ & $28(2.9)$ & $35(3.8)$ \\
\hline Somewhat hard & $84(9.4)$ & $99(14.5)$ & $108(11.2)$ & $176(19.2)$ \\
\hline Not very hard & $787(87.8)$ & $541(79.1)$ & $806(83.8)$ & $667(72.6)$ \\
\hline \multicolumn{5}{|l|}{ Physical activity } \\
\hline \multirow[t]{2}{*}{ Inactive } & $34(3.8)$ & $25(3.6)^{*}$ & $47(4.9)$ & $94(10.2)^{*}$ \\
\hline & $144(16.1)$ & $69(10.0)$ & $177(18.4)$ & $184(20.0)$ \\
\hline \multirow[t]{2}{*}{ Moderately active } & $391(43.7)$ & $298(43.3)$ & $419(43.6)$ & $430(46.7)$ \\
\hline & $205(22.9)$ & $125(18.2)$ & $191(19.9)$ & $100(10.9)$ \\
\hline Very active & $120(13.5)$ & $171(24.9)$ & $127(13.2)$ & $112(12.2)$ \\
\hline \multicolumn{5}{|l|}{ Current smoking } \\
\hline Yes & $155(17.3)$ & $228(33.3)^{*}$ & $150(15.6)$ & $233(25.2)^{*}$ \\
\hline No & $741(82.7)$ & $458(66.7)$ & $811(84.4)$ & $691(74.8)$ \\
\hline \multicolumn{5}{|l|}{ Sleep quality } \\
\hline Very bad & $5(0.6)^{*}$ & $19(2.8)$ & $12(1.3)$ & $24(2.6)$ \\
\hline Fairly bad & $127(14.2)$ & $70(10.2)$ & $138(14.4)$ & $150(16.3)$ \\
\hline good & $268(30.0)$ & $241(35.1)$ & $289(30.1)$ & $296(32.2)$ \\
\hline Fairly good & $319(35.7)$ & $219(31.9)$ & $326(34.0)$ & $287(31.3)$ \\
\hline Very good & $174(19.5)$ & $137(20.0)$ & $195(20.2)$ & $161(17.6)$ \\
\hline
\end{tabular}

${ }^{1} n=320$

${ }^{*} P<.05$ for comparison between race, within gender category. 
TABLE 3: Multivariate models for predictors of body mass index in the CARDIA study stratified by gender $(\beta, 95 \% \text { CI })^{1}$.

\begin{tabular}{|c|c|c|c|c|c|c|}
\hline \multirow{2}{*}{ Variable } & \multicolumn{3}{|c|}{ Men } & \multicolumn{3}{|c|}{ Women } \\
\hline & Model 1 & Model 2 & Model 3 & Model 1 & Model 2 & Model 3 \\
\hline \multirow{2}{*}{ Sleep (h) } & -0.20 & -0.20 & -0.14 & -0.33 & -0.29 & -0.17 \\
\hline & $(-0.40,0.002)$ & $(-0.41,0.01)$ & $(-0.34,0.07)$ & $(-0.53,-0.13)^{*}$ & $(-0.50,-0.09)^{*}$ & $(-0.37,0.02)$ \\
\hline \multirow{2}{*}{ Age (yrs) } & 0.003 & 0.004 & -0.02 & 0.12 & 0.13 & 0.12 \\
\hline & $(-0.06,0.07)$ & $(-0.07,0.07)$ & $(-0.09,0.05)$ & $(0.05,0.20)^{*}$ & $(0.06,0.20)^{*}$ & $(0.05,0.19)^{*}$ \\
\hline Race & -0.72 & -1.17 & -1.40 & -4.49 & -3.28 & -3.14 \\
\hline (White versus Black) & $(-1.23,-0.22)^{*}$ & $(-1.72,-0.62)^{*}$ & $(-1.94,-0.86)$ & $(-5.03,-3.94)^{*}$ & $(-3.88,-2.68)^{*}$ & $(-3.72,-2.57)^{*}$ \\
\hline \multicolumn{2}{|l|}{ Current smoker } & -1.54 & -1.54 & & -0.47 & -0.50 \\
\hline \multicolumn{2}{|l|}{ (Yes versus No) } & $(-2.18,-0.89)^{*}$ & $(-2.17,-0.91)^{*}$ & & $(-1.17,0.23)$ & $(-1.17,0.18)$ \\
\hline \multicolumn{2}{|l|}{ Number } & -0.06 & -0.06 & & -0.09 & -0.06 \\
\hline \multicolumn{2}{|l|}{ drinks/week } & $(-0.10,-0.03)^{*}$ & $(-0.09,-0.02)^{*}$ & & $(-0.15,-0.03)^{*}$ & $(-0.11,0.0005)$ \\
\hline \multirow{2}{*}{\multicolumn{2}{|c|}{ Education (yrs) }} & -0.12 & -0.15 & & -0.32 & -0.30 \\
\hline & & $(-0.23,-0.009)^{*}$ & $(-0.26,-0.04)^{*}$ & & $(-0.44,-0.19)^{*}$ & $(-0.42,-0.18)^{*}$ \\
\hline \multirow{2}{*}{\multicolumn{2}{|c|}{$\begin{array}{l}\text { Income } \\
\text { (ordinal 1-9) }\end{array}$}} & 0.20 & 0.21 & & -0.33 & -0.25 \\
\hline & & $(0.04,0.35)^{*}$ & $(0.06,0.36)$ & & $(-0.47,-0.18)^{*}$ & $(-0.40,-0.11)^{*}$ \\
\hline \multicolumn{2}{|l|}{ Work full-time } & -0.06 & 0.18 & & 0.65 & 0.71 \\
\hline \multicolumn{2}{|l|}{ (Yes versus No) } & $(-0.83,0.71)$ & $(-0.57,0.93)$ & & $(0.08,1.21)^{*}$ & $(0.17,1.25)$ \\
\hline \multirow{2}{*}{ Physical activity } & & & -1.04 & & & -1.57 \\
\hline & & & $(-1.27,-0.81)^{*}$ & & & $(-1.80,-1.33)^{*}$ \\
\hline
\end{tabular}

${ }^{1}$ Beta $(\beta)$ coefficients reported are unstandardized estimated regression coefficients calculated using predictor variables after they have been transformed and then rescaled via linear transformations to their original mean and variance.

$* P<.05$.

TABLE 4: Multivariate models for predictors of waist circumference in the CARDIA study stratified by gender $(\beta, 95 \% \text { CI })^{1}$.

\begin{tabular}{|c|c|c|c|c|c|c|}
\hline \multirow{2}{*}{ Variable } & \multicolumn{3}{|c|}{ Men } & \multicolumn{3}{|c|}{ Women } \\
\hline & Model 1 & Model 2 & Model 3 & Model 1 & Model 2 & Model 3 \\
\hline \multirow{2}{*}{ Sleep $(\mathrm{h})$} & -0.40 & -0.35 & -0.15 & -0.54 & -0.44 & -0.16 \\
\hline & $(-0.90,0.11)$ & $(-0.89,-0.18)$ & $(-0.67,0.36)$ & $(-1.01,-0.07)^{*}$ & $(-0.90,0.02)$ & $(-0.60,0.28)$ \\
\hline \multirow{2}{*}{ Age (yrs) } & 0.22 & 0.24 & 0.17 & 0.38 & 0.40 & 0.36 \\
\hline & $(0.05,0.38)^{*}$ & $(0.08,0.41)^{*}$ & $(0.008,0.33)$ & $(0.21,0.54)^{*}$ & $(0.24,0.56)^{*}$ & $(0.21,0.52)$ \\
\hline Race & 0.98 & 0.39 & -0.36 & -8.31 & -5.69 & -5.39 \\
\hline (White versus Black) & $(-0.22,2.18)$ & $(-0.93,1.72)$ & $(-1.63,0.91)$ & $(-9.53,-7.09)^{*}$ & $(-7.01,-4.37)^{*}$ & $(-6.65,-4.13)$ \\
\hline Current smoker & & -2.93 & -2.91 & & 0.25 & 0.18 \\
\hline (Yes versus No) & & $(-4.48,-1.39)^{*}$ & $(-4.39,-1.43)^{*}$ & & $(-1.32,1.83)$ & $(-1.32,1.69)$ \\
\hline Number & & -0.10 & -0.07 & & -0.16 & -0.08 \\
\hline drinks/week & & $(-0.19,-0.006)^{*}$ & $(-0.16,0.02)$ & & $(-0.29,-0.03)$ & $(-0.21,0.04)$ \\
\hline \multirow{2}{*}{ Education (yrs) } & & -0.43 & -0.51 & & -0.72 & -0.68 \\
\hline & & $(-0.70,-0.16)^{*}$ & $(-0.77,-0.25)^{*}$ & & $(-1.00,-0.45)^{*}$ & $(-0.95,-0.42)$ \\
\hline Income & & 0.35 & 0.45 & & -0.79 & -0.62 \\
\hline (ordinal 1-9) & & $(<0.001,0.70)^{*}$ & $(0.12,0.79)$ & & $(-1.11,-0.46)^{*}$ & $(-0.93,0.30)$ \\
\hline \multirow{2}{*}{ Physical activity } & & & -3.33 & & & -3.58 \\
\hline & & & $(-3.88,-2.78)$ & & & $(-4.11,-3.06)^{*}$ \\
\hline
\end{tabular}

${ }^{1}$ Beta $(\beta)$ coefficients reported are unstandardized estimated regression coefficients calculated using predictor variables after they have been transformed and then rescaled via linear transformations to their original mean and variance. 
of older Spanish adults, waist circumference was not related to sleep duration [23]. Results from the Quebec Family Study also showed larger waist circumference in men and women who reported sleeping $<7 \mathrm{~h} /$ night compared to those who reported sleeping $7-8 \mathrm{~h} /$ night [24]. It is possible that the age difference between the Spanish cohort and our young adult cohort is responsible for the different results. This relationship between waist circumference and sleep duration is of importance since well-known metabolic disturbances are associated with increased waist circumference [25].

In our study, BMI and waist circumference were inversely associated with sleep duration in women before including physical activity in our model. In men, associations tended to be in the same direction and of similar magnitude, but were not statistically significant. This gender difference has not been consistently reported in adults. In fact, no gender effect on the association of sleep and BMI was observed in an elderly Spanish cohort [23], a primary care U.S. sample [26], or the Quebec Family Study [24]. However, in a sample of Southern France, sleep duration was found to be related to BMI in women but not men [27]. Gangswisch et al. [9] have previously reported that BMI was higher in men and women who slept less than 7 hours compared to those who slept 7 hours or more only in individuals age $32-49$. This age group includes the age group of our cohort (33-45 years). In the NHANES data, gender differences were also observed in the association between BMI and sleep duration, with women being progressively more likely to be obese as sleep duration was reduced below $7 \mathrm{~h} /$ night whereas men were more likely to be obese with 6 or fewer hours of sleep/night. In our study, the association between BMI and sleep duration was significant in women but a trend in men. Our data add to the body of literature suggesting that sleep may have a slightly greater impact on body composition in adult women than in men. This potential gender difference in the relationship between sleep and adiposity deserves further exploration, especially since discordant data have also been observed in children and adolescents $[10,11,28,29]$. Previous metabolic studies have been conducted in young men only $[30,31]$ or in a study with few women [32]. Future metabolic studies should be done in women to determine if they have a different hormonal response to short sleep duration than men.

Our finding that percent body fat was not significantly associated with sleep duration is novel. One previous study has examined the relationship between this body composition measure and sleep duration in adults [24]. In our cohort, we did not find any significant association between these two variables. In the Quebec Family Study, Chaput et al. [33] found lower percent body fat in men and women who reported sleeping 7-8 h/night compared to those reporting 5-6 hours of sleep per night. It is possible that our sample size was not sufficient to detect an association. In fact, only 320 subjects participated in the DXA measurement, leaving few participants within each race-gender category. In comparison, the Quebec Family Study had more than twice our sample size with only one racial group.

In this study, adding physical activity to our models attenuated or abolished the relationship between sleep duration and body composition. We can speculate that sleep may in part act on body composition via changes in physical activity. It is possible that adults who sleep less are too tired to be physically active or those who sleep very long have too little time to be physically active. In fact, in our data, physical activity tended to increase with increasing sleep duration in women (data not shown). Moreover, being physically active can improve sleep quality and duration [34, 35] such that physical activity and sleep can be positively related.

Conservation of energy is a well-known principle that applies to obesity research. In this principle, energy is neither created nor lost. Therefore, in order to lose weight, one must expend more energy than is consumed or consume less energy than is expended; to gain weight, one must expend less energy than is consumed or consume more energy than is expended. It thus follows that our hypothesis explaining the relationship between sleep duration and body composition must (short of variations in energy partitioning) be due to an effect of sleep on energy expenditure or energy intake. If one controls for energy intake (food consumption) and energy expenditure (not equivalent, but closely related to physical activity), much of the variance in body composition variables is accounted for. This was the case when we added physical activity level to our models. In addition, food intake may be increased in those who sleep less. An increase in food intake with shorter sleep duration may result from various factors; longer hours awake create more time for eating, and hunger may increase with shorter sleep duration. Increased hunger ratings have been reported with short sleep duration and these have been related to reduced leptin and increased ghrelin levels [33]. Furthermore, in a recent report from the Quebec Family Study, the relationship between sleep duration and adiposity measures disappeared after controlling for leptin levels [24]. In fact, $88 \%$ of short sleepers had low leptin levels, confirming a previous clinical study showing that short sleep decreases leptin concentrations [33]. Dietary information was not taken at Y15 in the CARDIA study and we could not include this variable in our models.

Our study has several limitations. First, our sleep data are self-reported. Sleep was objectively measured in a subsample of our cohort [38]. In that study it was shown that the correlation between self-reported sleep duration and actigraph-measured sleep duration was 0.47. Furthermore, there was a systematic overestimation of sleep duration that was greater in short sleepers than in those sleeping more than $7 \mathrm{~h} /$ night. Also, self-reported sleep duration by obese individuals tended to be more closely related to actigraphmeasured sleep duration than lean individuals, who tended to overestimate their sleep duration in self-reports relative to the actigraph measurement. Thus, obese individuals may provide more accurate self-reports of their sleep duration than nonobese individuals and nonobese individuals overreport their sleep times. These data suggest that longer sleep hours would falsely include a greater proportion of lean individuals than obese individuals. This might then lead one to erroneously conclude that BMI decreases with increasing sleep duration even if this were not actually the case. In fact, Knutson and Lauderdale [36] have reported that the odds 
ratio for overweight in adolescents using time-diary sleep times was not significantly affected by sleep duration whereas the odds ratio for overweight was significantly increased with reduced sleep duration when sleep duration was selfreported. On the other hand, Nixon et al. [37] found a significant inverse association between actigraphy-measured sleep duration and overweight/obesity in 7-year old children. Similarly, Taheri et al. [7] found a significant U-shaped relationship between sleep duration and BMI when sleep was measured using polysomnography. More research is needed to determine the degree of error introduced by biased sleep reporting into the association of sleep duration and obesity.

Finally, our data show that the relationship between sleep duration and body composition is not affected by race but rather differs according to gender. In fact, women show a more consistent effect of sleep duration on body composition than men. Our data thus suggest that short sleep duration may be a risk factor for overall and abdominal obesity in young Black and White women. However, our overall small sample size, self-reported measures of sleep, and the cross-sectional nature of our data do not allow us to make definitive conclusions on the impact of gender on the relationship between sleep duration and obesity. More studies are needed to examine the gender difference on the relationship between sleep and obesity and consideration must be given to objectively-measured sleep duration.

\section{Acknowledgment}

Work on this manuscript was supported in part by contracts to the University of Alabama at Birmingham (Coordinating Center, N01-HC-95095; Field Center N01-HC-48047); the University Minnesota (Field Center, N01-HC-48048); Northwestern University (Field Center, N01-HC-48049); Kaiser Foundation Research Institute (N01-HC-48050) from the National Heart, Lung, and Blood Institute; and NIH grant P30DK056336. The opinions expressed herein are those of the authors and do not necessarily reflect those of the NIH or any other organization with which the authors are affiliated. None of the authors have any conflict of interest to disclose.

\section{References}

[1] S. W. Keith, D. T. Redden, P. T. Katzmarzyk, et al., "Putative contributors to the secular increase in obesity: exploring the roads less traveled," International Journal of Obesity, vol. 30, no. 11, pp. 1585-1594, 2006.

[2] P. F. Adams and C. A. Schoenborn, "Health behaviors of adults: United States, 2002-2004," Vital and Health Statistics. Series 10, no. 230, pp. 1-140, 2006.

[3] J. A. Walsleben, V. K. Kapur, A. B. Newman, et al., "Sleep and reported daytime sleepiness in normal subjects: the Sleep Heart Health Study," Sleep, vol. 27, no. 2, pp. 293-298, 2004.

[4] D. S. Lauderdale, K. L. Knutson, L. L. Yan, et al., "Objectively measured sleep characteristics among early-middle-aged adults: the CARDIA study," American Journal of Epidemiology, vol. 164, no. 1, pp. 5-16, 2006.

[5] G. T. C. Ko, J. C. N. Chan, A. W. Y. Chan, et al., "Association between sleeping hours, working hours and obesity in Hong
Kong Chinese: the 'better health for better Hong Kong' health promotion campaign," International Journal of Obesity, vol. 31, no. 2, pp. 254-260, 2007.

[6] B. Bjorvatn, I. M. Sagen, N. Øyane, et al., "The association between sleep duration, body mass index and metabolic measures in the Hordaland Health Study," Journal of Sleep Research, vol. 16, no. 1, pp. 66-76, 2007.

[7] S. Taheri, L. Lin, D. Austin, T. Young, and E. Mignot, "Short sleep duration is associated with reduced leptin, elevated ghrelin, and increased body mass index," PLoS Medicine, vol. 1, no. 3, article e62, 2004.

[8] N. D. Kohatsu, R. Tsai, T. Young, et al., "Sleep duration and body mass index in a rural population," Archives of Internal Medicine, vol. 166, no. 16, pp. 1701-1705, 2006.

[9] J. E. Gangwisch, D. Malaspina, B. Boden-Albala, and S. B. Heymsfield, "Inadequate sleep as a risk factor for obesity: analyses of the NHANES I," Sleep, vol. 28, no. 10, pp. 12891296, 2005.

[10] J.-P. Chaput, M. Brunet, and A. Tremblay, "Relationship between short sleeping hours and childhood overweight/obesity: results from the 'Québec en Forme' project,' International Journal of Obesity, vol. 30, no. 7, pp. 1080-1085, 2006.

[11] K. L. Knutson, "Sex differences in the association between sleep and body mass index in adolescents," Journal of Pediatrics, vol. 147, no. 6, pp. 830-834, 2005.

[12] M. Sekine, T. Yamagami, K. Handa, et al., "A dose-response relationship between short sleeping hours and childhood obesity: results of the Toyama Birth Cohort Study," Child: Care, Health and Development, vol. 28, no. 2, pp. 163-170, 2002.

[13] E. K. Snell, E. K. Adam, and G. J. Duncan, "Sleep and the body mass index and overweight status of children and adolescents," Child Development, vol. 78, no. 1, pp. 309-323, 2007.

[14] S. R. Patel, A. Malhotra, D. P. White, D. J. Gottlieb, and F. B. $\mathrm{Hu}$, "Association between reduced sleep and weight gain in women," American Journal of Epidemiology, vol. 164, no. 10, pp. 947-954, 2006.

[15] J.-P. Chaput, J.-P. Després, C. Bouchard, and A. Tremblay, "The association between sleep duration and weight gain in adults: a 6-year prospective study from the Quebec Family Study," Sleep, vol. 31, no. 4, pp. 517-523, 2008.

[16] S. R. Patel and F. B. Hu, "Short sleep duration and weight gain: a systematic review," Obesity, vol. 16, no. 3, pp. 643-653, 2008.

[17] I. Janssen, S. B. Heymsfield, D. B. Allison, D. P. Kotler, and R. Ross, "Body mass index and waist circumference independently contribute to the prediction of nonabdominal, abdominal subcutaneous, and visceral fat," The American Journal of Clinical Nutrition, vol. 75, no. 4, pp. 683-688, 2002.

[18] A. A. Hedley, C. L. Ogden, C. L. Johnson, M. D. Carroll, L. R. Curtin, and K. M. Flegal, "Prevalence of overweight and obesity among US children, adolescents, and adults, 19992002," The Journal of the American Medical Association, vol. 291, no. 23, pp. 2847-2850, 2004.

[19] X. Chen, M. A. Beydoun, and Y. Wang, "Is sleep duration associated with childhood obesity? A systematic review and meta-analysis," Obesity, vol. 16, no. 2, pp. 265-274, 2008.

[20] G. D. Friedman, G. R. Cutter, R. P. Donahue, et al., "CARDIA: study design, recruitment, and some characteristics of the examined subjects," Journal of Clinical Epidemiology, vol. 41, no. 11, pp. 1105-1116, 1988.

[21] S. Sidney, C. E. Lewis, J. O. Hill, et al., "Association of total and central adiposity measures with fasting insulin in a biracial population of young adults with normal glucose tolerance: the 
CARDIA study," Obesity Research, vol. 7, no. 3, pp. 265-272, 1999.

[22] G. E. P. Box and P. W. Tidwell, "Transformation of the independent variables," Technometrics, vol. 4, pp. 531-550, 1962.

[23] E. López-García, R. Faubel, L. León-Muñoz, M. C. Zuluaga, J. R. Banegas, and F. Rodríguez-Artalejo, "Sleep duration, general and abdominal obesity, and weight change among the older adult population of Spain," The American Journal of Clinical Nutrition, vol. 87, no. 2, pp. 310-316, 2008.

[24] J.-P. Chaput, J.-P. Després, C. Bouchard, and A. Tremblay, "Short sleep duration is associated with reduced leptin levels and increased adiposity: results from the Québec family study," Obesity, vol. 15, no. 1, pp. 253-261, 2007.

[25] W. Shen, M. Punyanitya, J. Chen, et al., "Waist circumference correlates with metabolic syndrome indicators better than percentage fat," Obesity, vol. 14, no. 4, pp. 727-736, 2006.

[26] R. D. Vorona, M. P. Winn, T. W. Babineau, B. P. Eng, H. R. Feldman, and J. C. Ware, "Overweight and obese patients in a primary care population report less sleep than patients with a normal body mass index," Archives of Internal Medicine, vol. 165, no. 1, pp. 25-30, 2005.

[27] M. Cournot, J.-B. Ruidavets, J.-C. Marquié, Y. Esquirol, B. Baracat, and J. Ferrières, "Environmental factors associated with body mass index in a population of Southern France," European Journal of Cardiovascular Prevention and Rehabilitation, vol. 11, no. 4, pp. 291-297, 2004.

[28] C. Padez, I. Mourão, P. Moreira, and V. Rosado, "Prevalence and risk factors for overweight and obesity in Portuguese children," Acta Paediatrica, vol. 94, no. 11, pp. 1550-1557, 2005.

[29] Y. Yu, B. S. Lu, B. Wang, et al., "Short sleep duration and adiposity in Chinese adolescents," Sleep, vol. 30, no. 12, pp. 1688-1697, 2007.

[30] K. Spiegel, R. Leproult, M. L'Hermite-Balériaux, G. Copinschi, P. D. Penev, and E. Van Cauter, "Leptin levels are dependent on sleep duration: relationships with sympathovagal balance, carbohydrate regulation, cortisol, and thyrotropin," The Journal of Clinical Endocrinology \& Metabolism, vol. 89, no. 11, pp. 5762-5771, 2004.

[31] K. Spiegel, R. Leproult, and E. Van Cauter, "Impact of sleep debt on metabolic and endocrine function," The Lancet, vol. 354, no. 9188, pp. 1435-1439, 1999.

[32] A. V. Nedeltcheva, J. M. Kilkus, J. Imperial, K. Kasza, D. A. Schoeller, and P. D. Penev, "Sleep curtailment is accompanied by increased intake of calories from snacks," The American Journal of Clinical Nutrition, vol. 89, no. 1, pp. 126-133, 2009.

[33] K. Spiegel, E. Tasali, P. Penev, and E. Van Cauter, "Brief communication: sleep curtailment in healthy young men is associated with decreased leptin levels, elevated ghrelin levels, and increased hunger and appetite," Annals of Internal Medicine, vol. 141, no. 11, pp. 846-850, 2004.

[34] A. C. King, L. A. Pruitt, S. Woo, et al., "Effects of moderateintensity exercise on polysomnographic and subjective sleep quality in older adults with mild to moderate sleep complaints," The Journals of Gerontology Series A, vol. 63, no. 9, pp. 997-1004, 2008.

[35] A. C. King, R. F. Oman, G. S. Brassington, D. L. Bliwise, and W. L. Haskell, "Moderate-intensity exercise and self-rated quality of sleep in older adults: a randomized controlled trial," The Journal of the American Medical Association, vol. 277, no. 1, pp. 32-37, 1997.
[36] K. L. Knutson and D. S. Lauderdale, "Sleep duration and overweight in adolescents: self-reported sleep hours versus time diaries," Pediatrics, vol. 119, no. 5, pp. e1056-e1062, 2007.

[37] G. M. Nixon, J. M. D. Thompson, D. Y. Han, et al., "Short sleep duration in middle childhood: risk factors and consequences," Sleep, vol. 31, no. 1, pp. 71-78, 2008.

[38] D. S. Lauderdale, K. L. Knutson, L. L. Yan, K. Liu, and P. J. Rathouz, "Self-reported and measured sleep duration: how similar are they?" Epidemiology, vol. 19, no. 6, pp. 838-845, 2008. 


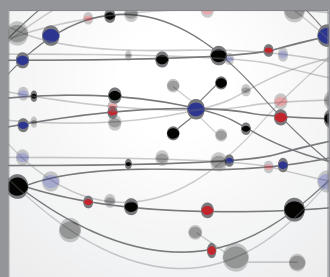

The Scientific World Journal
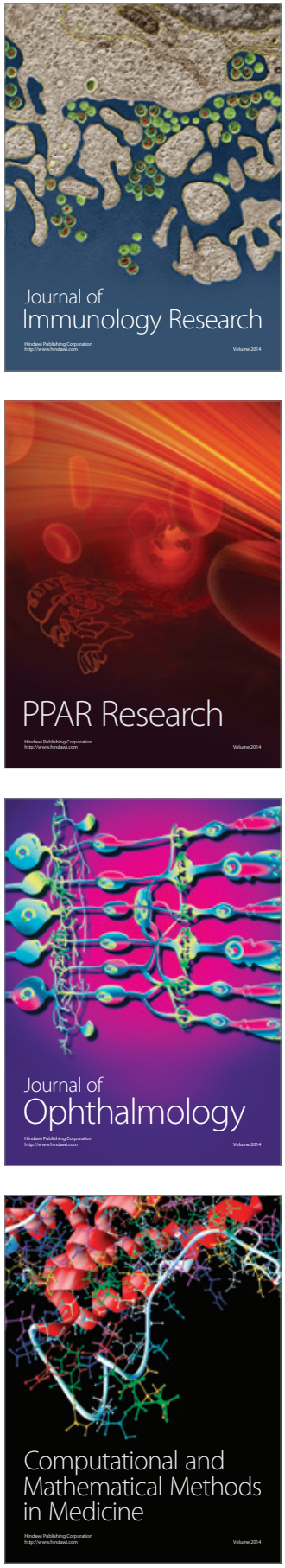

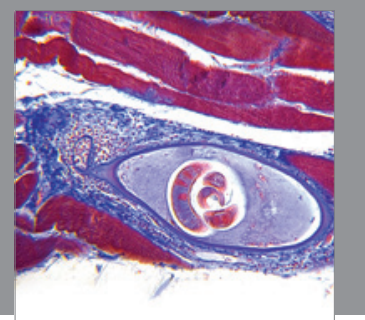

Gastroenterology

Research and Practice
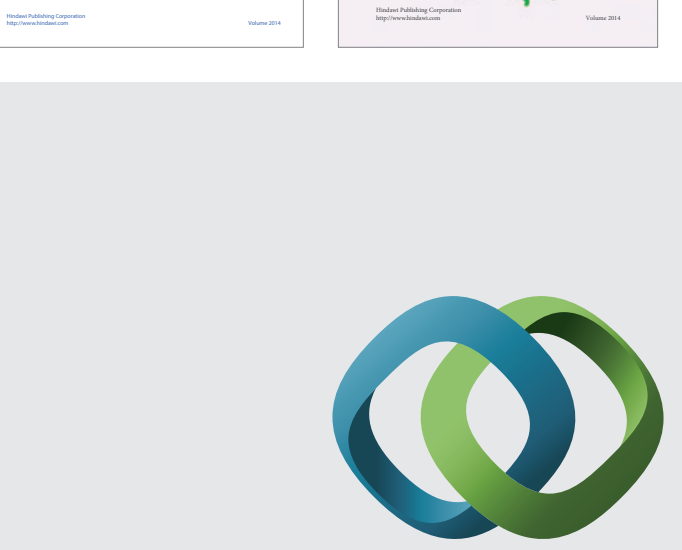

\section{Hindawi}

Submit your manuscripts at

http://www.hindawi.com
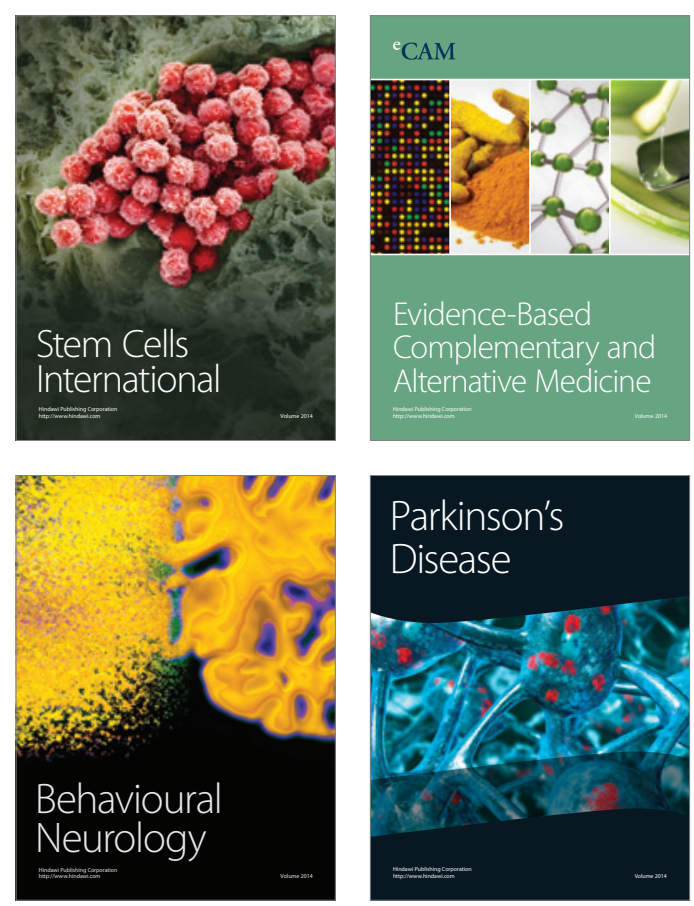

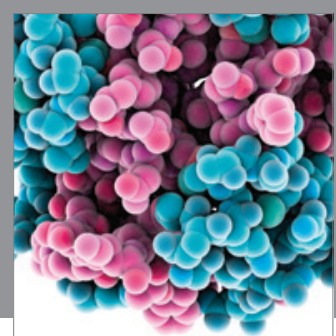

Journal of
Diabetes Research

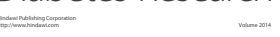

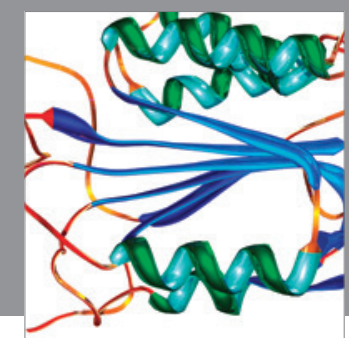

Disease Markers
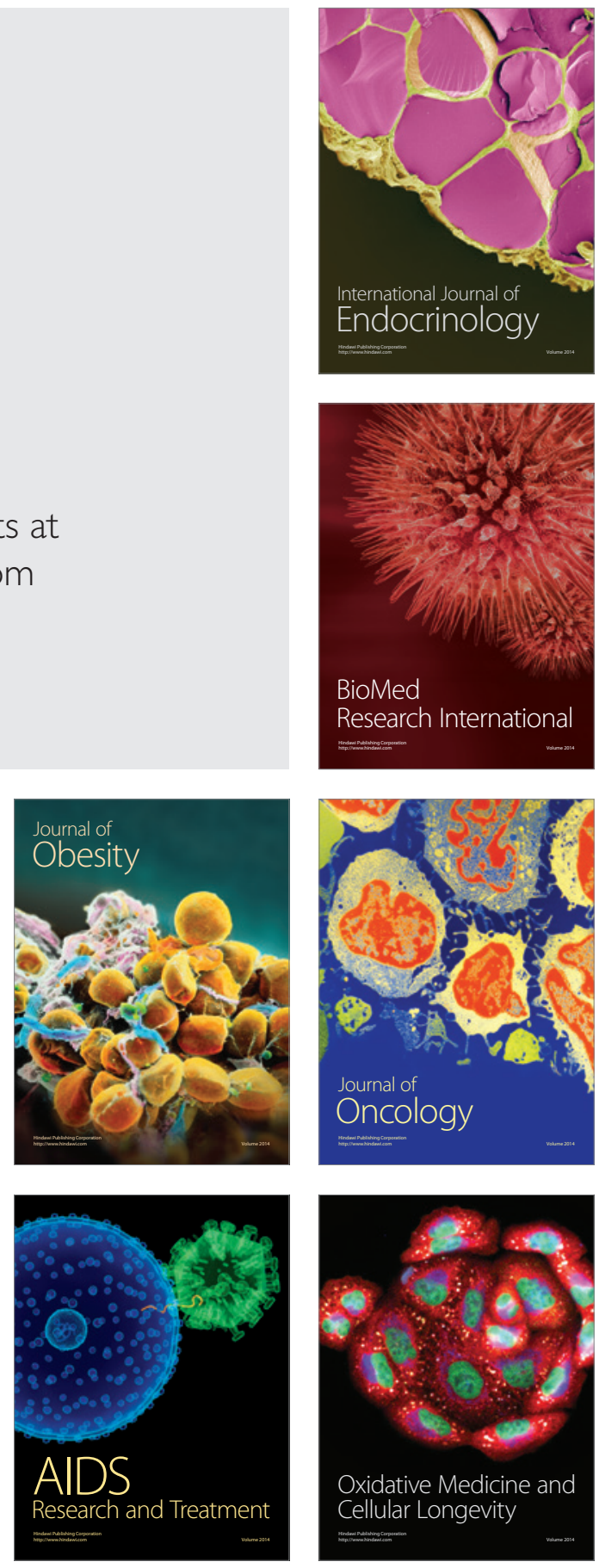